\title{
Is respiratory exchange ratio an alternative to estimate anaerobic threshold in trained runners?
}

\section{A razão de troca respiratória é uma alternativa para estimar o limiar anaeróbio em corredores treinados?}

Fernando Diefenthaeler ${ }^{1}$

Raphael Luiz Sakugawa

Rodolfo André Dellagrana ${ }^{1,2}$

Bruno Follmer ${ }^{-1}$

Elisa Cristina Lemos ${ }^{1}$

Wagner de Campos ${ }^{2}$
Abstract - Several studies showed that respiratory exchange ratio (RER) have been used as an alternative to evaluate the aerobic capacity in a single incremental test. However, few studies have investigated trained runners. The aim of this study was to verify if the respiratory exchange ratio (RER) could be used as an alternative criterion for estimating anaerobic threshold (AT) in long-distance runners. Nineteen male long-distance runners volunteered to participate in the study. An incremental treadmill test was performed with initial speed of $10 \mathrm{~km} \cdot \mathrm{h}^{-1}$ with increments of $1 \mathrm{~km} \cdot \mathrm{h}^{-1}$ every 1 min until voluntary exhaustion. The variables measured were oxygen uptake $\left(\mathrm{VO}_{2}\right)$, first and second ventilatory thresholds ( $\mathrm{VT}_{1}$ and $\mathrm{VT}_{2}$, respectively), intensity corresponding to RER level of $1.0\left(\mathrm{iRER}_{1.0}\right.$ ), peak velocity $(\mathrm{PV})$, heart rate $(\mathrm{HR})$, and rate of perceived exertion (RPE). One-way repeated measure analysis variance was used, following Bonferroni post hoc test. Agreement between parameters was evaluated by Pearson correlation and dispersion error. There were no significant differences between $\mathrm{iRER}_{1.0}$ and $\mathrm{VT}_{2}$ parameters. The correlations were significant between $\mathrm{iRER}_{1.0}$ and $\mathrm{VT}_{2}$ parameters for absolute and relative $\mathrm{VO}_{2}$, speed, and $\mathrm{HR}(\mathrm{r}=0.95 ; \mathrm{r}=0.60 ; \mathrm{r}=0.72 ; \mathrm{r}=0.81$, respectively). A small mean error $\left(-0.2 \mathrm{~km} \cdot \mathrm{h}^{-1}\right)$ was observed between iRER 1.0 and $\mathrm{VT}_{2}$. However, it was also observed an overestimation trend for high speeds. In conclusion, ${ }_{1 R E R}$ can be used as an alternative method to detect AT in long distance runners. However, its use is limited in runners with high aerobic capacity.

Key words: Athletic performance; Aerobic exercise; Oxygen consumption.

Resumo - Diversos estudos demonstram que a razão de troca respiratória (RER) tem sido utilizada como uma alternativa para estimar a capacidade aeróbia em único teste incremental. No entanto, poucos estudos foram realizados com corredores treinados. Sendo assim, o objetivo do estudo foi avaliar a utilização do RER como uma alternativa para estimar o limiar anaeróbio (AT) em corredores de longa distância. Dezenove corredores de longa distância do sexo masculino participaram do estudo. Foi realizado um teste incremental com velocidade inicial de $10 \mathrm{~km} \cdot \mathrm{h}^{-1}$ com incrementos de $1 \mathrm{~km} \cdot \mathrm{h}^{-1}$ a cada minuto até a exaustão voluntária. As variáveis mensuradas foram consumo de oxigênio $\left(V O_{2}\right)$, limiares ventilatórios $\left(V T_{1}\right.$ e $\left.V T_{2}\right)$, intensidade correspondente ao RER no valor igual a 1,O (iRER 1.0$)$, pico de velocidade $(P V)$, frequência cardiaca (HR) e percepção subjetiva de esforço (RPE). Foi realizada a análise de variância de medidas repetidas do tipo one-way, seguido do teste post hoc de Bonferroni. A relação entre as variáveis foi verificada pela correlaçấo de Pearson e a concordância por meio da medida de dispersão dos erros. Não houve diferença significativa entre as variáveis $i R E R_{1.0} e V T_{2}$. Foram encontradas correlaçôes significativas entre as variáveis $i R E R_{1.0}$ e $V T_{2}$ para os valores absolutos e relativos de $V O$, velocidade e $H R(r=0,95 ; r=0,60 ; r=0,72 ; r=0,81$, respectivamente). Um pequeno erro médio $\left(-0,2 \mathrm{~km} \cdot \mathrm{h}^{-1}\right)$ foi observado entre $i R E R_{1.0}$ e VT2, bem como uma tendência de superestimação em altas velocidade. Em conclusão, iRER 1.0 pode ser utilizado como um método alternativo para detectar o AT em corredores de longa distância, entretanto, seu uso é limitado em corredores com alta capacidade aeróbia.

Palavras-chave: Consumo de oxigênio; Desempenho atlético; Exercício aeróbio.
1 Federal University of Santa Catarina. Florianópolis, SC. Brazil.

2 Federal University of Paraná. Curitiba, PR. Brazil.

Received: 23 February 2017 Accepted: 25 March 2017 


\section{INTRODUCTION}

In general, the anaerobic threshold (AT) is the highest sustained exercise intensity where oxygen uptake $\left(\mathrm{VO}_{2}\right)$ can account for all of the energy requirement ${ }^{1}$. AT is also key predictor of discriminate aerobic endurance performance ${ }^{2}$ and represents the intensity at which the rate of removal of blood lactate equals the rate of blood lactate appearance. This concept is often considered the maximal lactate steady state (MLSS). MLSS is defined as the highest exercise intensity at which blood lactate concentration does not increase beyond the initial transient during constant load exercise ${ }^{3}$. MLSS has been considered the gold standard procedure ${ }^{4}$ since in most circumstances should represent the anaerobic threshold ${ }^{1}$. However, because MLSS is an invasive method and requires several constant load exercise trials to accurately determined, and may not be attractive for athletes and coaches $^{5,6}$. As an alternative, many researchers have used different methods to estimate MLSS during a single protocol from ventilatory parameters [i.e., pulmonary ventilation $\left(\mathrm{V}^{\mathrm{E}}\right)$ ]. These estimates are non-invasive, without blood sample collection ${ }^{6}$, and include estimating MLSS from ventilatory equivalents $\left(\mathrm{V}_{\mathrm{E}} / \mathrm{VO}_{2}\right)$, or $\mathrm{V}$-slope methods ${ }^{7}$.

Although some evidences show that ventilatory threshold (VT) can be related to lactate accumulation, it seems that both indices are not the same phenome ${ }^{8}$. VT presents two inflection points, in which first $\left(\mathrm{VT}_{1}\right)$ represents the upper limit between moderate and heavy-intensity, while second $\left(\mathrm{VT}_{2}\right)$ represents the upper limit between heavy and very heavyintensity ${ }^{9}$. Some studies have been related $\mathrm{VT}_{2}$ with respiratory exchange ratio $(\mathrm{RER})$ equal to $1.00\left(\mathrm{iRER}_{1.0}\right)^{10-12}$. It has long been known that beyond this point "extra" carbon dioxide $\left(\mathrm{CO}_{2}\right)$ is released, as product of the bicarbonate buffering system, associated with lactate accumulation ${ }^{10,13}$. Thus, $\mathrm{iRER}_{1.0}$ could be considerate a fast determination method since it has been related to MLSS during incremental cycle ergometer protocols ${ }^{10,11}$.

During an incremental cycle ergometer protocol, it is possible to obtain fingertip or ear lobe blood samples without interruption. However, during treadmill running, blood sampling requires at least $30 \mathrm{~s}$ pauses between incremental exercise stages that may compromise comparisons between ventilatory and blood lactate variables ${ }^{5}$. In a study involving 14 middle distance runners, Leti et al..$^{5}$ observed that the intensity associated with iRER $_{1.0}$ was similar to MLSS, but significantly different from intensity corresponding to $\mathrm{VT}_{2}$. However, these authors observed a disagreement between $\mathrm{iRER}_{1.0}$ and MLSS in five subjects evaluated. According to the authors, blood sample collection interruption during the constant-load MLSS trials ( 2 min every $5 \mathrm{~min}$ ) could allowed the subject to recover and overestimate MLSS speed.

Therefore, the validity of $\mathrm{iRER}_{1.0}$ to estimate aerobic capacity in running is still unclear due to protocols limitations and different methodological procedures. Moreover, blood sampling from the ear lobe without interruption during an incremental treadmill protocols is impracticable. Hence, 
$\mathrm{iRER}_{1.0}$ predicted by a continuous running protocol with high ecological validity for runners may lead to a better alternative than protocols with interruptions. In addition, several studies have suggested shorter protocols to identify individual athlete thresholds for better exercise prescription in runners ${ }^{4,5,9}$. Thus, $\mathrm{iRER}_{1.0}$ may allow a quick, objective determination of intensity associated with AT during a submaximal protocol and without blood collection ${ }^{11}$. Although gas analyzer provides respiratory outcomes to estimate both VT and RER, iRER $_{1.0}$ is a more objective index to estimate AT than other methods since it does not require data fitting or subjective examination of the results, as is often the case in determining $\mathrm{VT}^{2}$. Furthermore, $\mathrm{iRER}_{1.0}$ is independent of evaluator's experience in identify AT. In this way, the aim of this study was to verify if RER could be used as an alternative criterion for estimating anaerobic threshold in long-distance runners.

\section{METHODOLOGICAL PROCEDURES}

Nineteen male long-distance runners volunteered to participate in this study. The mean and standard deviation age, height, body mass, body mass index, and body fat were $17.89 \pm 0.94$ years, $1.73 \pm 0.06 \mathrm{~m} ; 65.66$ $\pm 7.99 \mathrm{~kg} ; 21.75 \pm 1.70 \mathrm{~kg} / \mathrm{m}^{2}$, and $11.83 \pm 3.09 \%$, respectively. Subjects were free of injuries or symptoms six months prior to the assessment. Average training patterns for the runners were six days per week and 70 $\mathrm{km}$ of training distance per week. Moreover, individual average time for the $5 \mathrm{~km}$ distance event was $18.47 \pm 1.15 \mathrm{~min}$. All volunteers signed an informed consent form in agreement with the local Human Research Ethics Committee (protocol: 0064.0.091.000-10) and performed according to the Declaration of Helsinki.

Body mass was measured on a scale with $0.1 \mathrm{~kg}$ resolution (Toledo, model 2096, São Paulo, Brazil). Height was measured with a stadiometer with $0.1 \mathrm{~cm}$ resolution (Sanny, São Paulo, Brazil). Body fat percentage was estimated from the equation of 2 skinfolds (tricipital and calf) proposed by Slaughter ${ }^{14}$ for adolescents, with the use of an adipometer with $0.1 \mathrm{~mm}$ resolution (WCS Technology, Curitiba, Brazil). After this, all subjects performed a maximal incremental running exercise on a motorized treadmill (Imbramed Super ATL, Porto Alegre, RS, Brazil). The treadmill was set at $1 \%$ gradient ${ }^{15}$. The initial speed was set at $10 \mathrm{~km} \cdot \mathrm{h}^{-1}$ for $1 \mathrm{~min}$ and was incremented by $1 \mathrm{~km} \cdot \mathrm{h}^{-1}$ every $1 \mathrm{~min}$ until voluntary exhaustion. Throughout the test respiratory and pulmonary gas exchange variables were measured using a breath-by-breath gas analyzer (True One Metabolic Measurement System ${ }^{\varpi}$ 2400, Parvo Medics, Salt Lake City, USA). The equipment was calibrated with known gas samples for oxygen $\left(\mathrm{O}_{2}\right)$ and $\mathrm{CO}_{2}$, while ventilation flow was measured using a heated pneumotachometer, which was calibrated prior to each test with a fixed 3-L volume manual syringe (Hans Rudolf, USA). RPE was assessed during the last $15 \mathrm{~s}$ of each stage, using the OMNI scale ${ }^{16}$, which consists of 11 statements scored from 0 
to 10. HR was also monitored throughout the tests (Polar Electro, Oy, Finland). $\mathrm{VO}_{2}, \mathrm{VT}_{1}, \mathrm{VT}_{2}$, RER, peak velocity (PV), heart rate (HR), and $\mathrm{RPE}$ were continuously monitored during the test.

To achieve the maximum oxygen uptake $\left(\mathrm{VO}_{2 \mathrm{MAX}}\right)$ required, participants had to meet at least two of the following criteria: (a) plateau in $\mathrm{VO}_{2}$ (change of $<150 \mathrm{~mL} \cdot \mathrm{min}^{-1}$ in the last two stages); (b) RER $\geq 1.10$; (c) peak $\mathrm{HR}$ at the end of the test $\geq 95 \%$ of age predicted maximum (220-age), and (d) $\mathrm{RPE} \geq 9$. Therefore, $\mathrm{VO}_{2 \mathrm{MAX}}$ was defined as the highest $\mathrm{VO}_{2}$ value attained after reaching the aforementioned criteria. Maximal heart rate $\left(\mathrm{HR}_{\mathrm{MAX}}\right)$ was defined as the highest value recorded during the test. The PV was defined as the last velocity maintained for a full minute.

The $\mathrm{VT}_{1}$ was determined by the excess $\mathrm{CO}_{2}$ method $\left(\mathrm{ExCO}_{2}\right)^{2}$. $\mathrm{VT}_{2}$ was determined by an increase in both ventilatory equivalents $\left(\mathrm{V}_{\mathrm{E}} / \mathrm{VO}_{2}\right.$ and $\left.\mathrm{V}_{\mathrm{E}} / \mathrm{VCO}_{2}\right)$ and a decrease in partial pressure of end-tidal carbon dioxide $\left(\mathrm{PETCO}_{2}\right)^{11}$. A visual inspection was carried out independently by two experienced investigators to determine the speed associated with $\mathrm{VT}_{1}$ and $\mathrm{VT}_{2}$. The speeds detected were then compared between investigators. If both values were within $3 \%$, then those values were averaged and accepted. If the difference was higher than 3\%, a third investigator would independently analyze the ventilation test data to detect $\mathrm{VT}_{1}$ and $\mathrm{VT}_{2}$. This third value was then compared with those initial investigators, if this value was within 3\% either of the initial investigators, then those two values were averaged.

iRER $_{1.0}$ was determined using a previously described procedure ${ }^{11}$. If iRER $_{1.0}$ occurred between the beginning and the $15^{\text {th }}$ second of the stage, the chosen speed corresponded to the previous stage. When $\mathrm{iRER}_{1.0} \mathrm{oc}^{-}$ curred between $15^{\text {th }}$ and $30^{\text {th }}$ second of the stage, the chosen speed was the one corresponded to the previous stage $+0.25 \mathrm{~km} \cdot \mathrm{h}^{-1}$; between the $30^{\text {th }}$ and $45^{\text {th }}$ second of the stage, the chosen speed corresponded to the previous stage $+0.5 \mathrm{~km} \cdot \mathrm{h}^{-1}$, and between the $45^{\text {th }}$ and $59^{\text {th }}$ second of the stage, the chosen speed was the one corresponded to the previous stage $+0.75 \mathrm{~km} \cdot \mathrm{h}^{-1}$. Two experience investigators identified these events. In case of disagreement, a third investigator would independently analyze those events.

Data normality was verified using Shapiro-Wilk test. Values are presented as mean and standard deviation (SD). One-way repeated measures analysis of variance was used to compare the $\mathrm{VO}_{2}, \mathrm{PV}, \mathrm{HR}, \mathrm{iRER}_{1.0}$, and $\mathrm{RPE}$ with $\mathrm{VT}_{1}, \mathrm{VT}_{2}, \mathrm{iRER}_{1.0}$, and exercise intensity (speed) at which $\mathrm{VO}_{2 \mathrm{MAX}}$ occurs $\left(\mathrm{iVO}_{2 \mathrm{MAX}}\right.$ ). Upon finding a significant F-ratio, Bonferroni post hoc test was used to locate the differences between subjects and approaches. The Pearson product-moment correlation coefficient was used to verify the relationship between each parameter. Agreements were sought by the Bland-Altman method ${ }^{17}$. The correlation coefficients were classified as very weak to negligible (0.0 to 0.2$)$, weak ( 0.2 to 0.4$)$, moderate (0.4 to 0.7 ), strong (0.7 to 0.9$)$, and very strong (0.9 to 1.0$)^{18}$. The level of significance was set at 0.05 . 


\section{RESULTS}

The small variation in $\mathrm{VO}_{2 \mathrm{MAX}}$ (coefficient of variance $-\mathrm{CV}=7.4 \%$ ) and $\mathrm{PV}$ $(\mathrm{CV}=4.7 \%)$ showed homogeneity among athletes. The parameters obtained during the incremental test are shown in Table 1 . There was no significant difference between $\mathrm{iRER}_{1.0}$ and $\mathrm{VT}_{2}$ for any of the variables measured. Speed, percentage of the maximal speed, RER, and RPE differed statistically from iRER 1.0 and $\mathrm{iVO}_{2 \mathrm{MAX}}$. All variables showed significant differences between $\mathrm{iRER}_{1.0}$ and $\mathrm{VT}_{1}$.

Table 1. Mean and standard deviation of speed, percentage of the maximal speed ( $\left.\operatorname{Speed}_{\mathrm{MAX}}\right)$, oxygen uptake $\left(\mathrm{VO}_{2}\right)$, heart rate (HR), respiratory exchange ratio (RER), and rate of perceived exertion (RPE) at ventilatory thresholds (VT and $\mathrm{VT}_{2}$ ), intensity corresponding to RER level of 1.0 (iRER ${ }_{1.0}$ ), and intensity (speed) at which maximal oxygen uptake occurs ( $\mathrm{iVO}_{2} \mathrm{max}$ ).

\begin{tabular}{lcccc}
\hline & $\mathrm{VT}_{1}$ & iRER $_{1.0}$ & $\mathrm{VT}_{2}$ & $\mathrm{iVO}_{2} \mathrm{max}$ \\
\hline Speed $\left(\mathrm{km} \cdot \mathrm{h}^{-1}\right)$ & $13.63 \pm 1.26^{\mathrm{a}, \mathrm{b}, \mathrm{c}}$ & $16.34 \pm 2.14^{\mathrm{c}}$ & $16.58 \pm 1.30^{\mathrm{c}}$ & $18.32 \pm 0.86$ \\
Speed $_{\text {MAX }}(\%)$ & $74.40 \pm 5.95^{\mathrm{a}, \mathrm{b}, \mathrm{c}} \mathrm{c}$ & $89.15 \pm 10.55^{\mathrm{c}}$ & $90.46 \pm 5.47^{\mathrm{c}}$ & 100 \\
$\mathrm{VO}_{2}\left(\mathrm{~L} \cdot \mathrm{min}^{-1}\right)$ & $3.31 \pm 0.41^{\mathrm{a}, \mathrm{b}, \mathrm{c}}$ & $3.79 \pm 0.68^{\mathrm{c}}$ & $3.74 \pm 0.52^{\mathrm{c}}$ & $4.09 \pm 0.57$ \\
$\mathrm{VO}_{2}\left(\mathrm{~mL} \cdot \mathrm{kg}^{-1} \cdot \mathrm{min}^{-1}\right)$ & $50.72 \pm 5.24^{\mathrm{a}, \mathrm{b}, \mathrm{c}} \mathrm{c}$ & $57.73 \pm 6.58^{\mathrm{c}}$ & $56.77 \pm 4.84^{\mathrm{c}}$ & $62.36 \pm 4.61$ \\
$\mathrm{HR}(\mathrm{bpm})$ & $166 \pm 13^{\mathrm{a}, \mathrm{b}, \mathrm{c}}$ & $183 \pm 10^{\mathrm{c}}$ & $181 \pm 11^{\mathrm{c}}$ & $190 \pm 11$ \\
$\mathrm{RER}$ & $0.89 \pm 0.05^{\mathrm{a}, \mathrm{b}, \mathrm{c}}$ & $1.00 \pm 0.0^{\mathrm{c}}$ & $0.97 \pm 0.05^{\mathrm{c}}$ & $1.10 \pm 0.06$ \\
$\mathrm{RPE}$ & $4.1 \pm 1.6^{\mathrm{a}, \mathrm{b}, \mathrm{c}}$ & $6.7 \pm 1.6^{\mathrm{c}}$ & $6.0 \pm 1.1^{\mathrm{c}}$ & $9.1 \pm 1.3$ \\
\hline
\end{tabular}

${ }^{\mathrm{a}}$ significantly different from $\mathrm{iRER}_{1.0}$, ${ }^{\mathrm{b}}$ significantly different from $\mathrm{VT}_{2}$, ${ }^{\mathrm{c}}$ significantly different from $\mathrm{iVO}_{2} \max . \mathrm{p}<.05$.

Table 2 presents correlations between $\mathrm{iRER}_{1.0}, \mathrm{VT}_{1}$ and $\mathrm{VT}_{2}$ for absolute and relative $\mathrm{VO}_{2}$, speed, percentage of the maximal speed, $\mathrm{HR}$, and RPE.

Table 2.Values of Pearson's correlation between intensity corresponding to respiratory exchange ratio level of 1.0 (iRER $\mathrm{ino}_{1.0}$ ), first ventilatory threshold $\left(\mathrm{VT}_{1}\right)$, and second ventilatory threshold $\left(\mathrm{VT}_{2}\right)$ for absolute and relative oxygen uptake $\left(\mathrm{VO}_{2}\right)$, speed, percentage of the maximal speed $\left(\mathrm{Speed}_{\mathrm{MAX}}\right)$, heart rate (HR), and rate of perceived exertion (RPE).

\begin{tabular}{lcccc}
\hline iRER $_{1.0}$ & $\mathrm{VT}_{1}$ & Classification & $\mathrm{VT}_{2}$ & Classification \\
\hline $\mathrm{VO}_{2}\left(\mathrm{~L} \cdot \mathrm{min}^{-1}\right)$ & $0.83^{*}$ & $\mathrm{~S}$ & $0.95^{\star}$ & $\mathrm{VS}$ \\
$\mathrm{VO}_{2}\left(\mathrm{~mL} \cdot \mathrm{kg}^{-1} \cdot \mathrm{min}^{-1}\right)$ & $0.57^{*}$ & $\mathrm{M}$ & $0.60^{*}$ & $\mathrm{M}$ \\
Speed $\left.^{*} \mathrm{~km} \cdot \mathrm{h}^{-1}\right)$ & $0.71^{*}$ & $\mathrm{~S}$ & $0.72^{*}$ & $\mathrm{~S}$ \\
\%Speed $_{\mathrm{MAX}}$ & $0.65^{*}$ & $\mathrm{M}$ & $0.67^{*}$ & $\mathrm{M}$ \\
$\mathrm{HR}(\mathrm{bpm})$ & $0.79^{*}$ & $\mathrm{~S}$ & $0.81^{*}$ & $\mathrm{~S}$ \\
RPE & 0.30 & $\mathrm{~W}$ & 0.44 & $\mathrm{M}$ \\
\hline
\end{tabular}

Abbreviations are used for correlation coefficients classification (VW - very weak to negligible; $\mathrm{W}$ - weak; M - moderate; S - strong; VS - very strong). ${ }^{\star} p<.05$

Scatter diagram confirms that $\mathrm{iRER}_{1.0}$ and $\mathrm{VT}_{1}$ showed no agreement, demonstrating mean error of $2.7 \mathrm{~km} \cdot \mathrm{h}^{-1}$ (95\%IC, -0.3 to 5.7) (Figure 1).

Scatter diagram showed no statistically difference between both $\mathrm{iRER}_{1.0}$ and $\mathrm{VT}_{2}$ intensities, in which the mean error of estimative was -0.2 $\mathrm{km} \cdot \mathrm{h}^{-1}$ (95\%IC, -3.2 to 2.7 ) (Figure 2). However, a significant correlation coefficient was observed between difference $\left(\mathrm{iRER}_{1.0}-\mathrm{VT}_{2}\right.$ ) and mean, which indicate an important trend. Moreover, $\mathrm{CV}$ between variables was 9.8\% (mean of $\mathrm{iRER}_{1.0}-\mathrm{VT}_{2}$ ). 


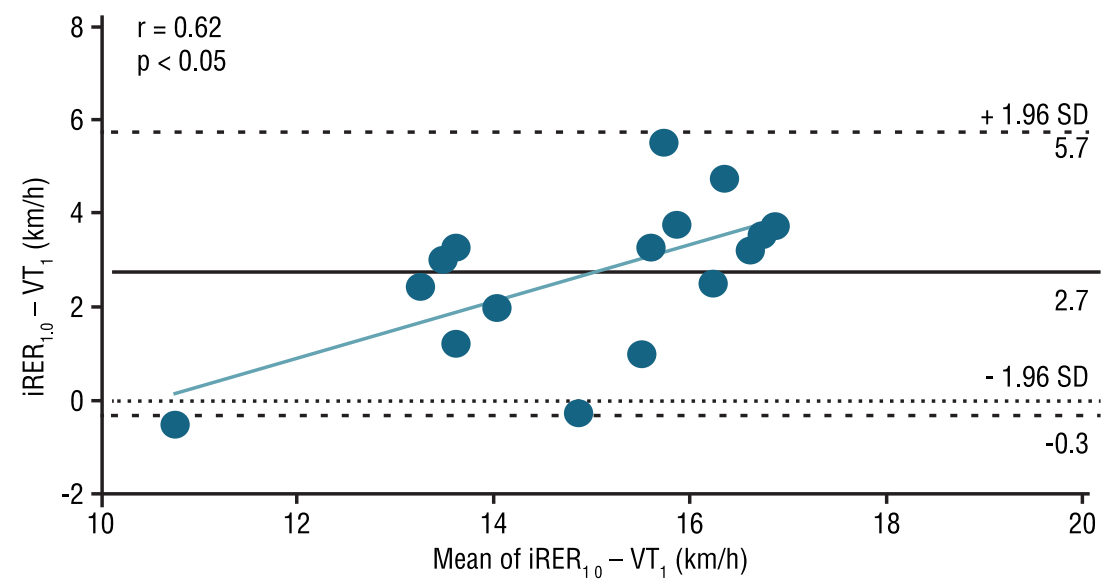

Figure 1. Analysis of the residual scores between intensity corresponding to respiratory exchange ratio level of 1.0 ( iRER $_{10}$ ) and first ventilatory threshold $\left(\mathrm{VT}_{1}\right)$ Solid line represents the mean error and dotted line represents the confidence interval (95\%).

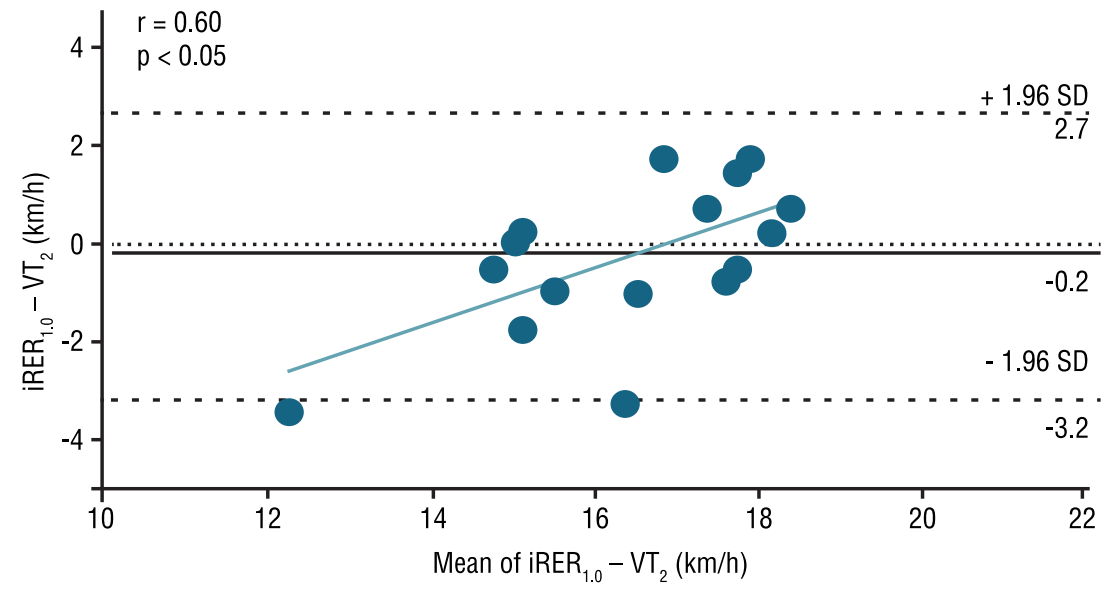

Figure 2. Analysis of the residual scores between intensity corresponding to respiratory exchange ratio level of 1.0 ( RER $_{1.0}$ ) and second ventilatory threshold $\left(\mathrm{VT}_{2}\right)$. Solid line represents the mean error and dotted line represents the confidence interval $(95 \%)$.

\section{DISCUSSION}

The aim of this study was to verify if RER could be used as an alternative criterion for estimating AT in long-distance runners. Results show that $\mathrm{iRER}_{1.0}$ presents high correlation coefficient and no difference with intensity associated with $\mathrm{VT}_{2}$ (Tables 1 and 2 ), suggesting that $\mathrm{iRER}_{1.0}$ could predict AT. However, this result must be carefully interpreted, due to moderate correlation coefficients observed between differences and mean in the scatter diagram (Figure 2). It was also observed an overestimation trend for $\mathrm{VT}_{2}$ at high speeds. Our results are partially in accordance with findings from previous studies ${ }^{5,10,11}$ that have compared iRER ${ }_{1.0}$ with different indices for estimate AT.

Different procedures have been used to identify AT, such as the nonlinearly increase of blood lactate concentration (lactate threshold) ${ }^{19}$, reaching a fixed value ${ }^{20}$, and a nonlinearly increasing of ventilation representing $\mathrm{VT}^{21}$. An advantage of using respiratory parameters to predict AT is that 
it is a more easy accessible and noninvasive technique. According previous studies, $\mathrm{VT}_{2}$ measurement during incremental exercise may provide a good estimate of the $\mathrm{AT}^{22,23}$. However, to measure VT after the maximal effort is necessary two evaluators with wide analysis experience. Therefore, a practical method and evaluator-independent to determine the optimal training intensity (considering aerobic-anaerobic transition as intensity prescription $)^{5}$ in a submaximal protocol with individual ventilatory responses can be useful for coaches and athletes. Also, according to Carey et $\mathrm{al}^{23}$ the possibility of develop a portable respiratory rate monitor (similar to heart rate monitors) would be interesting to monitor training intensity.

In the present study, treadmill gradient used was $1 \%$ since it best represents the energy cost in outdoor running ${ }^{15}$, improving intensity estimation precision for long distance runners. Additionally, assessment of ventilatory variables seems to be independent of exercise stages duration during an incremental maximal running test ${ }^{24}$. Thus, no significant difference was observed between $\mathrm{iRER}_{1.0}$ and $\mathrm{VT}_{2}$. Furthermore, Bland and Altman ${ }^{17}$ method showed a better agreement between $\mathrm{iRER}_{1.0}$ and $\mathrm{VT}_{2}$ than $\mathrm{VT}_{1}$ (see Figure 1 and 2). This results are in agreement with previous studies involving cycle ergometer ${ }^{10,11}$ and treadmill protocols ${ }^{5}$. The agreement between $\mathrm{iRER}_{1.0}$ and $\mathrm{VT}_{2}$ (except for two subjects, see Figure 2) was expected since RER indirectly represents muscle oxidative capacity $\left(\mathrm{CO}_{2}\right.$ production $/ \mathrm{O}_{2}$ uptake). Additionally, RER increases according to exercise intensity, demonstrating increase in carbohydrate metabolism and decrease in lipids contribution ${ }^{10}$. Once RER values are superior to 1.0 it indicates buffering of $\mathrm{H}^{+}$and consequently hyperventilation due to increment in $\mathrm{CO}_{2}$ production, corresponding to $\mathrm{VT}_{2}{ }^{10}$.

However, despite the small mean error observed $\left(-0.2 \mathrm{~km} \cdot \mathrm{h}^{-1}\right)$ confidence interval $(95 \% \mathrm{CI},-3.2$ to 2.7$)$ was large in comparison with other investigations ${ }^{5,11}$. Additionally, high CV (9.8\%) between mean of RER $_{1.0}$ and $\mathrm{VT}_{2}$ may indicate wide differences between variables, compromising individual analysis. In figure 2 , is possible to observe a trend indicating that in subjects with higher aerobic capacity the $\mathrm{iRER}_{1.0}$ may overestimate $\mathrm{VT}_{2}$. It partially corroborate with previous study conducted with long distance runners where a significant difference was observed in running speeds between $\mathrm{iRER}_{1.0}$ and $\mathrm{VT}_{2}{ }^{5}$. Regarding that aerobic-anaerobic transition is related with endurance performance ${ }^{25}$, some studies showed that RER values above 1.0 were correlated with running pace (speed) during competition ${ }^{26}$. It could be a possible elucidation for aerobic capacity overestimation using $\mathrm{iRER}_{1.0}$.

iRER $_{1.0}$ seems to be an easy way to assess aerobic capacity in cycle ergometer tests. Laplaud and Menier ${ }^{27}$ have demonstrated reproducibility of iRER $_{1.0}$ in active men, which was similar to $\mathrm{VT}_{2}$. Additionally, Laplaud et al. ${ }^{11}$ proposed that $\mathrm{iRER}_{1.0}$ determined during an incremental test allows a quicker and easier estimation of MLSS. Similar previous study showed that $\mathrm{iRER}_{1.0}$ can be used to estimate the onset of blood lactate accumulation at $3.5 \mathrm{mmol} \cdot \mathrm{L}^{-1}$, anaerobic threshold of abrupt lactate increase, and 
$\mathrm{VT}_{2}$ in active men ${ }^{10}$ and in trained cyclists ${ }^{23}$. Nevertheless, it is important to highlight that during a cycle ergometer test blood samples are taken without interruption, allowing comparison between ventilatory and blood lactate responses.

In runners, Leti et al. ${ }^{5}$ observed that $\mathrm{iRER}_{1.0}$ was different from $\mathrm{VT}_{2}$, but similar to MLSS. The experiment was performed in a gymnasium with changes in running direction every $25 \mathrm{~m}$. However, this exercise mode (i.e., constant changes of directions) cannot be compared with long-distance runner's specificity. Moreover, in a previous study comparing two running treadmill protocols (protocol 1 - increase in speed; protocol 2 - increase in speed and gradient), authors observed that RER presented lower reproducibility between protocols than others ventilatory response ${ }^{28}$, indicating that RER is protocol-dependent. In this way, it seems that terrain in the running (e.g., cross-country) could change ventilatory responses, increasing anaerobic contribution, and altering the relationship between performance and RER values ${ }^{26}$.

Among limitations of the present study, we can highlight the initial speed of the test $\left(10 \mathrm{~km} \cdot \mathrm{h}^{-1}\right)$ that might have overestimated $\mathrm{VT}_{1}$ and $\mathrm{VT}_{2}$. However, subjects were trained endurance runners with average speed of $16.30 \pm 1.06 \mathrm{~km} \cdot \mathrm{h}^{-1}$ in the $5 \mathrm{~km}$ event. Thus, initial speed correspond to $61.35 \%$ of average speed during competitions and probably is lower than $\mathrm{VT}_{1}{ }^{29}$. Additionally, the lack of an invasive method such as the assessment of lactate concentration, but interruptions for blood sampling collection could overestimate speed at AT as a consequence of athlete's recovery $\mathrm{y}^{4}$.

\section{CONCLUSION}

In conclusion, during an incremental treadmill test $\mathrm{iRER}_{1.0}$ can be used as an individual alternative method to detect the AT in long distance runners. However, its use is limited in runners with high aerobic capacity. Therefore, more studies should be conducted to develop specific submaximal protocols with short duration to validate simplified methods to estimate aerobic-anaerobic transition in long distance runners.

\section{REFERENCES}

1. Svedahl K, MacIntosh BR. Anaerobic threshold: the concept and methods of measurement. Can J Appl Physiol 2003;28(2):299-323.

2. Gaskill S, Ruby B, Walker A, Sanchez O, Serfass R, Leon A. Validity and reliability of combining three methods to determine ventilatory threshold. Med Sci Sports Exerc 2001;33(11):1841-8.

3. Tegtbur UWE, Busse MW, Braumann KM. Estimation of an individual equilibrium between lactate production and catabolism during exercise. Med Sci Sports Exerc 1993;25(5):620-7.

4. Faude O, Kindermann W, Meyer T. Lactate threshold concepts: how valid are they? Sports Med 2009;39(6):469-90.

5. Leti T, Mendelson M, Laplaud D, Flore P. Prediction of maximal lactate steady state in runners with an incremental test on the field. J Sports Sci 2012;30(6):609-16. 
6. Van Schuylenbergh R, Vanden Eynde B, Hespel P. Correlations between lactate and ventilatory thresholds and the maximal lactate steady state in elite cyclists. Int J Sports Med 2004;25(6):403-8.

7. Wasserman K. The anaerobic threshold measurement to evaluate exercise performance. Am Rev Respir Dis 1984;129(2 Pt 2):S35-40.

8. Denadai B. Limiar anaeróbio: considerações fisiológicas e metodológicas. Rev Bras Ativ Fís Saúde 2012;1(2):74-88.

9. Meyer T, Lucía A, Earnest CP, Kindermann W. A conceptual framework for performance diagnosis and training prescription from submaximal gas exchange parameters--theory and application. Int J Sports Med 2005;26 (Suppl 1):S38-48.

10. Zagatto A, Miyagi W, Sakugawa R, Kaminagakura E, Papoti M. Aerobic Endurance Measurement by Respiratory Exchange Ratio during a Cycle Ergometer Graded Exercise Test. J Exerc Physiol online 2012;15(5):49-56.

11. Laplaud D, Guinot M, Favre-Juvin A, Flore P. Maximal lactate steady state determination with a single incremental test exercise. Eur J Appl Physiol 2006;96(4):446-52.

12. Dickstein K, Aarsland T, Svanes H, Barvik S. A respiratory exchange ratio equal to 1 provides a reproducible index of submaximal cardiopulmonary exercise performance. Am J Cardiol 1993;71(15):1367-9.

13. Whipp BJ. Physiological mechanisms dissociating pulmonary $\mathrm{CO} 2$ and $\mathrm{O} 2$ exchange dynamics during exercise in humans. Exp Physiol 2007;92(2):347-55.

14. Slaughter, MH, Lohman, TG, Boilean, CA, Stillman, RJ, Vanvoan, ME, and Bemebn, DA. Skinfold equations for estimation of body fatness in children and youth. Hum Biol 1998;60(5):709-23.

15. Jones A, Doust J. A $1 \%$ treadmill grade most accurately reflects the energetic cost of outdoor running. J Sports Sci 1996;14(4):321-7.

16. Utter AC, Robertson RJ, Green JM, Suminski RR, Mcanulty SR, Nieman and DC. Validation of the Adult OMNI Scale of Perceived Exertion for Walking/ Running Exercise. Med Sci Sport Exerc 2004;36(10):1776-80.

17. Bland JM, Altman D. Statistical methods for assessing agreement between two methods of clinical measurement. Lancet 1986;327(8476):307-10.

18. Rowntree D. Statistics Without Tears. London: Penguin; 1991.

19. Coyle EF, Martin WH, Ehsani AA, Hagberg JM, Bloomfield SA, Sinacore DR, et al. Blood lactate threshold in some well-trained ischemic heart disease patients. J Appl Physiol 1983;54(1):18-23.

20. Heck H, Mader A, Hess G, Mucke S, Muller R, Hollmann W. Justification of the 4 mmol. 1- 1 lactate threshold. Int J Sport Med 1985;6(3):117-30.

21. Wasserman K, Whipp B, Koyal S, Beaver W. Anaerobic threshold and respiratory gas exchange during exercise. J Appl Physiol 1973;75(9 Suppl):S19-21.

22. Yamamoto Y, Miyashita M, Hughson R, Tamura S, Shinohara M, Mutoh Y. The ventilatory threshold gives maximal lactate steady state. Eur J Appl Physiol 1991;63(1):55-9.

23. Carey DG, Schwarz LA, Pliego GJ, Raymond RL. Respiratory Rate is a Valid and Reliable Marker for the Anaerobic Threshold: Implications for Measuring Change in Fitness. J Sports Sci Med 2005;4(4):482-8.

24. Kuipers H, Rietjens G, Verstappen F, Schoenmakers H, Hofman G. Effects of stage duration in incremental running tests on physiological variables. Int J Sports Med. 2003;24(7):486-91.

25. Dellagrana R, Guglielmo L, Santos B, Hernandez S, Silva S, Campos W. Physiological, Anthropometric, Strength, and Muscle Power Characteristics Correlates With Running Performance in Young Runners. J Strength Cond Res 2015;29(6):1584-91.

26. Bellar D, Judge L. Modeling and Relationship of Respiratory Exchange Ratio to Athletic Performance. J Strength Cond Res 2012;26(9):2484-9. 
27. Laplaud D, Menier R. Reproducibility of the instant of equality of pulmonary gas exchange and its physiological significance. J Sport Med Phys Fit 2003;43(4):437-43.

28. Tzvetkov $\mathrm{S}$. The reproducibility of the ventilatory anaerobic threshold determination methods among two maximal treadmill exercise protocols in elite orienteers. Phys Educ Sport 2009;7(1):45-53.

29. Dantas JL, Doria C. Detection of the Lactate Threshold in Runners: What is the Ideal Speed to Start an Incremental Test? J Hum Kinet 2015;45(1):217-24.

\section{CORRESPONDING AUTHOR}

Fernando Diefenthaeler Universidade Federal de Santa Catarina, Centro de Desportos - Laboratório de Biomecânica Campus Universitário da Trindade s/n. CEP: 88040-900 Florianópolis (SC), Brasil E-mail: fernando.diefenthaeler@ ufsc.br 